\title{
Evaluation of Net Energy Expenditures of Dairy Cows According to Body Weight Changes over a Full Lactation
}

\author{
J. L. Ellis, ${ }^{1}$ F. Qiao, ${ }^{2}$ and J. P. Cant \\ Centre for Nutrition Modelling, Department of Animal and Poultry Science, University of Guelph, Ontario, Canada, N1G 2W1
}

\begin{abstract}
Equations that predict daily dry matter intake (DMI) of a lactating cow could be evaluated by comparing the predicted accumulation of energy in body weight (BW) over the course of lactation with the observed BW evolution. However, to do so requires that first the energy balance calculations from observed DMI are evaluated. The purpose of the work reported here was to determine the degree of deviation of predicted from observed BW, according to net energy for lactation $\left(\mathrm{NE}_{\mathrm{L}}\right)$ balance calculated from weekly observations of DMI, BW, and fatcorrected milk production in 21 sets of full-lactation data, and to determine an appropriate correction of the $\mathrm{NE}_{\mathrm{L}}$ bias for subsequent DMI prediction evaluations. When the National Research Council maintenance equation $0.08 \times \mathrm{BW}(\mathrm{kg})^{0.75}$ was used in energy balance calculation, BW was overpredicted with an increasing difference between the cumulative predicted BW and observed BW as lactation progressed. Placing all the error of BW prediction into maintenance energy expenditures resulted in a best-fit equation of $0.096 \pm 0.003$ $\mathrm{Mcal} / \mathrm{kg}$ of $\mathrm{BW}^{0.75}$. A time-dependent equation was also developed, in which weekly maintenance expenditures were determined as the $\mathrm{NE}_{\mathrm{L}}$ expenditure to yield a zero $\mathrm{NE}_{\mathrm{L}}$ balance and could be described by a second-order polynomial equation related to week of lactation (WOL) where maintenance $\mathrm{NE}_{\mathrm{L}}=\left[-0.0227( \pm 0.0098) \times \mathrm{WOL}^{2}\right.$ $+1.352( \pm 0.456) \times \mathrm{WOL}+78.09( \pm 4.92) \mathrm{Mcal} / \mathrm{kg}$ of $\left.\mathrm{BW}^{0.75}\right] \times 10^{-3}$. Average maintenance energy expenditure at the onset of lactation was approximately 0.08 $\mathrm{Mcal} / \mathrm{kg}$ of $\mathrm{BW}^{0.75}$, and this value increased to a plateau at wk 15 of lactation of approximately $0.098 \mathrm{Mcal} / \mathrm{kg}$ of $\mathrm{BW}^{0.75}$. Standard deviations between data sets of weekly maintenance parameter estimates throughout lactation were large but consistent at approximately $25 \%$ of the mean. Revision of the maintenance energy expenditure estimate substantially improved BW prediction by the energy balance model. On average, the
\end{abstract}

\footnotetext{
Received October 2, 2005.

Accepted January 12, 2006.

${ }^{1}$ Corresponding author: jellis@uoguelph.ca

${ }^{2}$ Current address is Beijing Earth-Tech Advantages Inc., 2 Shangdi Xinxi Rd \#D501, Beijing, China 100085.
}

$0.096 \mathrm{Mcal}$ of $\mathrm{NE}_{\mathrm{I}} / \mathrm{kg}$ of $\mathrm{BW}^{0.75}$ equation resulted in the best BW predictions, although substantial variation existed around this value.

Key words: maintenance energy expenditure, energy balance, dairy cow

\section{INTRODUCTION}

With the advent of the dynamic computer model to describe biological systems, there has arisen the potential to predict the response of an animal over time to various interventions. In models of lactation, instantaneous milk production rates by dairy cows are typically calculated from rates of nutrient flow from the diet. In turn, DMI prediction equations typically require daily milk production and BW as inputs. Such equations carry an implicit description of energy balance between intake and use. In a static prediction at one point in time, there is little penalty to being off by a small fraction from the true energy balance. In a dynamic model, however, in which any imbalance between predicted intake and use of energy accumulates in body stores, a small deviation could rapidly escalate errors in BW prediction over simulated time.

In the process of developing approaches to predict daily DMI in a dynamic simulation of dairy cow performance, it is important to first evaluate and correct, if necessary, the energy accumulation in body stores implied from observed DMI and milk production rates. McNamara and Baldwin (2000) found, using a model of the metabolic transactions in the lactating cow (Baldwin, 1995), that in response to dietary changes, body fat accumulation was either over- or underpredicted in simulations of more than a few weeks. They concluded that the model's precision in predicting long-term dynamic changes in energy-utilizing reactions was inadequate. Heuer et al. (2001) also observed, in a model designed to predict herd mean $\mathrm{NE}_{\mathrm{L}}$ energy balance for the first $12 \mathrm{wk}$ of lactation (WOL), that the predicted $\mathrm{NE}_{\mathrm{L}}$ balance was generally higher than calculated $\mathrm{NE}_{\mathrm{L}}$ balance in all weeks of lactation. However, at the individual cow level, they observed that the standard deviation was often larger than the mean difference.

A companion paper (Ellis et al., 2006) describes the performance of selected DMI prediction equations in a 
Table 1. Summary of evaluation data sets

\begin{tabular}{|c|c|c|c|c|c|}
\hline $\begin{array}{l}\text { Data } \\
\text { set }\end{array}$ & Source & Treatment & Parity & $\mathrm{WOL}^{1}$ & $\mathrm{n}^{2}$ \\
\hline 1 & Mohrenweiser and Donker, 1967 & Diet 1 - Early alfalfa pre, early alfalfa postcalving & 1 & 2 to 39 & 9 \\
\hline 2 & Mohrenweiser and Donker, 1967 & Diet 2 - Early alfalfa pre, late alfalfa postcalving & 1 & 2 to 39 & 10 \\
\hline 4 & Mohrenweiser and Donker, 1967 & Diet 4 - Late alfalfa pre, late alfalfa postcalving & 1 & 2 to 40 & 10 \\
\hline 5 & Wohlt and Clark, 1978 & Diet 1 - no supplemental nitrogen & Mostly $>1$ & 1 to 42 & 10 \\
\hline 6 & Wohlt and Clark, 1978 & Diet 2 - urea & Mostly $>1$ & 1 to 42 & 10 \\
\hline 10 & DePeters et al., 1985 & $2 \times$ milking, $\mathrm{H}$ to $\mathrm{M}$ diet at $28 \mathrm{~kg} / \mathrm{d}, \mathrm{M}$ to $\mathrm{L}$ diet at $23 \mathrm{~kg} / \mathrm{d}^{3}$ & $>1$ & 1 to 42 & 12 \\
\hline 11 & DePeters et al., 1985 & $2 \times$ milking, $\mathrm{H}$ to $\mathrm{M}$ diet at $25 \mathrm{~kg} / \mathrm{d}, \mathrm{M}$ to $\mathrm{L}$ diet at $20 \mathrm{~kg} / \mathrm{d}^{3}$ & 1 & 1 to 42 & 7 \\
\hline 12 & DePeters et al., 1985 & $3 \times$ milking, $\mathrm{H}$ to $\mathrm{M}$ diet at $25 \mathrm{~kg} / \mathrm{d}, \mathrm{M}$ to $\mathrm{L}$ diet at $20 \mathrm{~kg} / \mathrm{d}^{3}$ & 1 & 1 to 42 & 8 \\
\hline 13 & DePeters et al., 1985 & $3 \times$ milking, $\mathrm{H}$ to $\mathrm{M}$ diet at $28 \mathrm{~kg} / \mathrm{d}, \mathrm{M}$ to $\mathrm{L}$ diet at $23 \mathrm{~kg} / \mathrm{d}^{3}$ & $>1$ & 1 to 42 & 13 \\
\hline 14 & Holter and Hayes, 1992 & CP balanced using 1 grain & 1 & 2 to 45 & 14 \\
\hline 15 & Holter and Hayes, 1992 & $\mathrm{CP}$ balanced using 2 grains & 1 & 2 to 45 & 14 \\
\hline 21 & Holter et al., 1993 & RUP protein-fat supplement & $>1$ & 2 to 37 & 13 \\
\hline
\end{tabular}

${ }^{1} \mathrm{WOL}=$ Week of lactation; period of time for which data set reported DMI, FCM, and BW.

${ }^{2}$ Number of animals used in treatment groups.

${ }^{3}$ Dietary treatment change; $\mathrm{H}$ = high energy, $\mathrm{M}=$ medium energy, and $\mathrm{L}=$ low energy diets, based on daily milk production for each cow.

dynamic model of energy flows in the lactating dairy cow. The test variable used to compare model predictions with observations, and thereby evaluate the DMI prediction equations, is the integrated instantaneous $\mathrm{NE}_{\mathrm{L}}$ balance, expressed as weekly BW throughout lactation. Published data on DMI, BW, and milk production over a full lactation were collected for this goal. To use a predicted $\mathrm{NE}_{\mathrm{L}}$ balance as the test variable, it was necessary to first evaluate $\mathrm{NE}_{\mathrm{L}}$ balances obtained from the observations alone. The purpose of the work reported here was to determine the degree of deviation of predicted from observed $\mathrm{BW}$ according to $\mathrm{NE}_{\mathrm{L}}$ balance calculated from observations in the collated data sets and to determine an appropriate correction of the bias for subsequent DMI prediction evaluations (Ellis et al., 2006). The bias was placed in maintenance expenditures so that a time-independent, as well as a timedependent, equation relating maintenance expenditures to WOL could be developed.

\section{MATERIALS AND METHODS}

\section{Data Sets}

The database used to evaluate predicted BW and determine a new description of maintenance energy expenditures consisted of 777 data points from 21 sets of lactation performance data averaged from groups of 7 to 22 Holstein cows (Table 1). Information about the data sets is summarized in Table 1. Criteria for data set selection were that weekly BW, DMI, and $4 \% \mathrm{FCM}$ production for at least $37 \mathrm{WOL}$ were reported and that information was given on parity and diet. Data plots from the publications were scanned into Adobe Photoshop Elements (Adobe Systems, Inc., San Jose, CA), a grid was snapped over the image, and lined up with the $\mathrm{x}$ - and $\mathrm{y}$-axes to an appropriate scale. Data points were extracted and recorded to 1 or 2 decimal places for each WOL.

\section{Energy Balance Model}

Energy balance at each WOL was calculated from daily $\mathrm{NE}_{\mathrm{L}}$ flows in $\mathrm{Mcal} / \mathrm{d}$ as:

$$
\mathrm{NE}_{\mathrm{L}} \text { Balance }=\mathrm{NE}_{\mathrm{L}} \text { Intake }
$$

$$
\text { - } \mathrm{NE}_{\mathrm{L}} \text { for Milk Production - } \mathrm{NE}_{\mathrm{L}} \text { for Maintenance }
$$

The $\mathrm{NE}_{\mathrm{L}}$ equivalents of body mass, according to $\mathrm{NRC}$ (1988), were assumed so that $\mathrm{BW}$ change $\left(\Delta \mathrm{BW}_{\mathrm{i}}\right)$ in kilograms per day was 0.203 times $\mathrm{NE}_{\mathrm{L}}$ balance (Mcal/ $\mathrm{d}$; equation 1) if the $\mathrm{NE}_{\mathrm{L}}$ balance was negative and 0.195 times $\mathrm{NE}_{\mathrm{L}}$ balance if positive. The older $\mathrm{NRC}$ (1988) factors were used because information on BCS, required for calculating the newer NRC (2001) factors, was not available from the data sets. Assuming a BCS of 3.5, BW change would be 0.196 and 0.171 times $\mathrm{NE}_{\mathrm{L}}$ balance for negative and positive balances, respectively, according to NRC (2001). Analysis showed that the 
model was relatively insensitive to a $15 \%$ change in $\mathrm{NE}_{\mathrm{L}}$ equivalents of body mass, and so the single NRC (1988) factors were used.

Predicted BW of cows starting at wk 3 of lactation was obtained from the initial observed BW at wk 2 of lactation adjusted for the predicted BW changes for that week $\left(\Delta \mathrm{BW}_{\mathrm{n}}\right)$. Similarly, the $\mathrm{BW}$ of cows at progressive WOL $\left(\mathrm{BW}_{\mathrm{n}+1}\right)$ was obtained from the previous predicted $\mathrm{BW}\left(\mathrm{BW}_{\mathrm{n}}\right)$ adjusted for that week's predicted $\mathrm{BW}$ changes $\left(\Delta \mathrm{BW}_{\mathrm{n}}\right)$ :

$$
B W_{n+1} \equiv B W_{n}+\Delta B W_{n} \cdot 7
$$

Maintenance $\mathrm{NE}_{\mathrm{L}}$ expenditures were calculated as $0.08 \mathrm{Mcal}$ of $\mathrm{NE}_{\mathrm{I}} / \mathrm{kg}$ of $\mathrm{BW}^{0.75}$ (NRC, 2001) where $\mathrm{BW}$ was the predicted, not the observed value, to simulate a dynamic system. The $\mathrm{NE}_{\mathrm{L}}$ intake was calculated as observed DMI $(\mathrm{kg} / \mathrm{d})$ multiplied by the energy content of the feed, estimated for each WOL by the NRC (2001) computer formulation program, from information on diet composition provided in each publication. Assumptions were that pregnancy commenced at 90 DIM, age at first calving was $24 \mathrm{mo}$, calving interval was $12 \mathrm{mo}$, BCS was 3.5 , calf birth weight was $45 \mathrm{~kg}$, and no animals were grazing. If lactation number was greater than 1, mature BW was set to the observed value at the onset of lactation. For first-lactation cows, mature BW was calculated as 1.25 times observed BW at the start of lactation (NRC, 2001). Milk production was entered as $\mathrm{kg}$ of FCM, $4 \%$ milk fat, $3 \%$ true protein, and $4.78 \%$ lactose.

The NRC (2001) feed library was used, with modifications, when chemical composition of the feed was provided. When diet $\mathrm{NE}_{\mathrm{L}}$ values were provided in the publications, the NRC (2001) program was still used to calculate $\mathrm{NE}_{\mathrm{L}}$. This ensured that all diet $\mathrm{NE}_{\mathrm{L}}$ values were obtained from the same set of assumptions.

Net energy $\left(\mathrm{NE}_{\mathrm{L}}\right)$ for milk production was the observed FCM production $(\mathrm{kg} / \mathrm{d})$ multiplied by $0.749 \mathrm{Mcal}$ of $\mathrm{NE}_{\mathrm{L}} / \mathrm{kg}$ (NRC, 2001).

Extra energy expenditures by first-lactation heifers was calculated according to the NRC (2001) for a BCS of 3.5 as $0.0103 \mathrm{Mcal}$ of $\mathrm{NE}_{\mathrm{L}} / \mathrm{kg}$ of $\mathrm{SBW}^{0.75}$, where SBW is shrunk BW $=0.96 \times \mathrm{BW}$.

\section{Statistical Analyses}

Mean square prediction error (MSPE) for each of the 21 data sets was calculated as:

$$
M S P E=\sum_{i=1}^{n}\left(O_{i}-P_{i}\right)^{2} / n
$$

where $\mathrm{n}$ is the number of observations, $\mathrm{O}_{\mathrm{i}}$ is the observed value, and $\mathrm{P}_{\mathrm{i}}$ is the predicted value. Square root of the MSPE, expressed as a proportion of the observed mean, gave an estimate of the overall prediction error. The MSPE was decomposed into random error, error due to deviation of the predicted vs. observed regression slope from unity, and error due to overall bias (Bibby and Toutenburg, 1977).

Predictions were also evaluated by examining the slope and intercept of predicted vs. observed BW for the 21 sets of lactation data. Using PROC MEANS in SAS (SAS Institute, 2000), the slopes and intercepts were tested for significant difference from the line of unity (slope of one, intercept of zero). To identify patterns of bias in the predictions, residual BW (predicted - observed) was regressed against WOL and predicted $\mathrm{BW}$, and the average linear and quadratic coefficients of the plots were tested against zero using PROC MEANS in SAS. Mean predicted BW over the full lactation was compared against the observed means by $t$ test, where $\mathrm{n}=21$.

To account for the bias detected in predicted energy balance, maintenance energy expenditures, in Mcal/kg of BW ${ }^{0.75}$, were estimated for each of the 21 data sets as the value that minimized residual sum of squares (RSS) between predicted and observed BW from wk 4 through 37 of lactation. Weekly maintenance energy expenditures were also calculated from the weekly DMI, FCM yield, and BW observations as the value that yielded a $\mathrm{NE}_{\mathrm{L}}$ balance of zero; that is, predicted $\mathrm{BW}_{\mathrm{n}}=$ observed $\mathrm{BW}_{\mathrm{n}}$.

\section{RESULTS}

\section{Evaluation of the Original Energy Balance Model}

Simulations with maintenance calculated as 0.08 Mcal of $\mathrm{NE}_{\mathrm{L}} / \mathrm{kg}$ of $\mathrm{BW}^{0.75}$ in the energy balance model showed an overall trend for BW to be overpredicted as lactation progressed (Figure 1). The average intercept of the predicted vs. observed regression line $(-884.6 \pm$ 192.6) was significantly different from zero, and the average slope $(2.70 \pm 0.38)$ was significantly different from $1(P<0.05)$. There was a trend for residual BW to increase with WOL (Figure 1) and with predicted $\mathrm{BW}$, and the plots could be described by significant linear and quadratic equations (linear equation for residual vs. WOL slope $=2.92 \pm 0.66$, intercept $=-13.74$ \pm 2.28 and linear equation for residual vs. predicted $\mathrm{BW}$ slope $=0.52 \pm 0.12$, intercept $=-281.86 \pm 59$ ).

Predicted BW mean $(602.8 \pm 2.1 \mathrm{~kg})$ was significantly different from the observed mean $(558.2 \pm 3.4 \mathrm{~kg})$, and the majority of prediction error was due to regression and bias, whereas only $27 \%$ of MSPE was from random sources. 

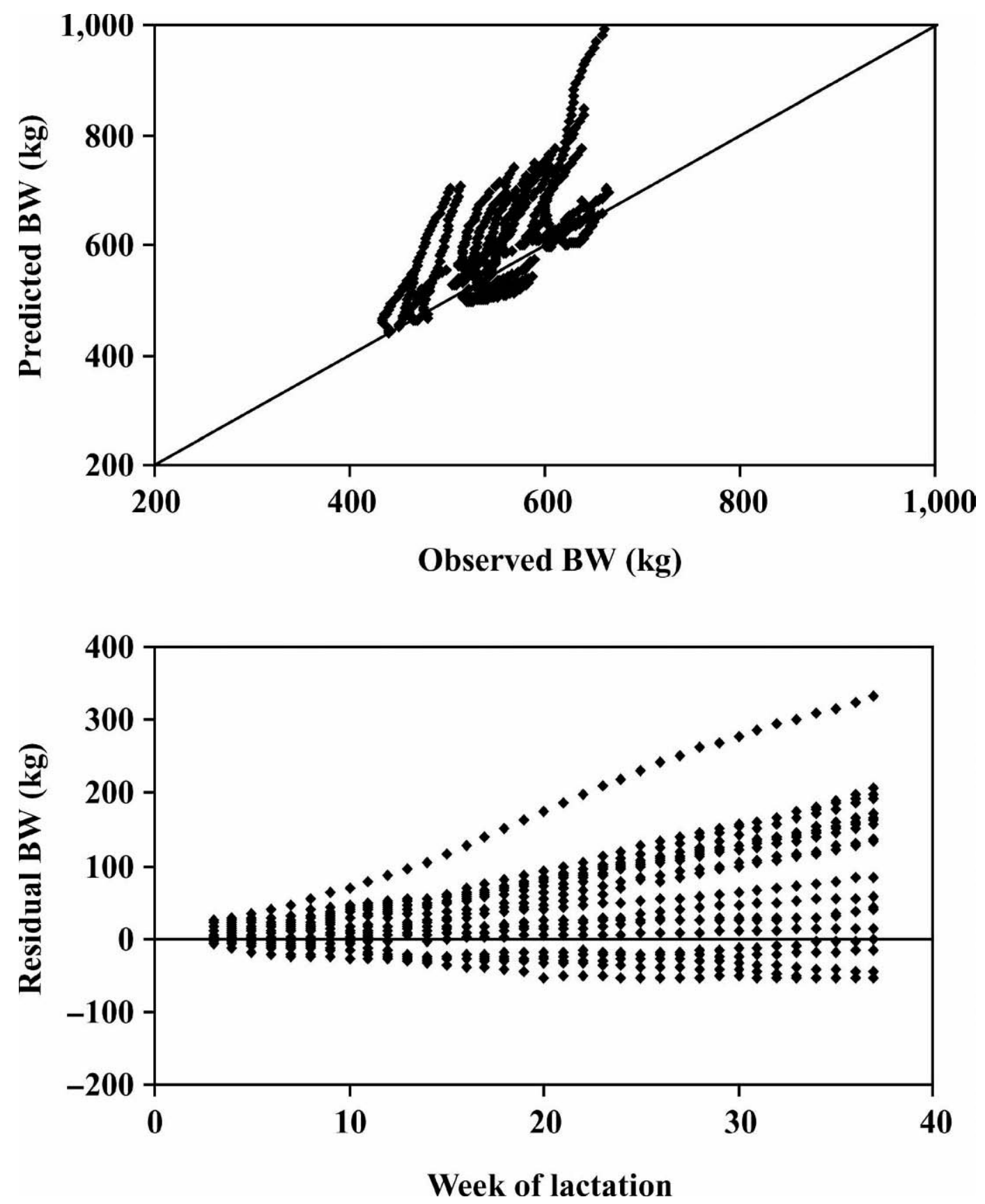

Figure 1. Predicted vs. observed BW (top) and residual (Predicted - Observed) BW vs. week of lactation (bottom) for evaluation of the energy balance model using the original $0.08 \mathrm{Mcal}$ of $\mathrm{NE}_{\mathrm{L}} / \mathrm{kg}$ of $\mathrm{BW}^{0.75}$ maintenance equation.

\section{New Maintenance Descriptions}

In an attempt to correct the bias in BW prediction, an optimum estimate of maintenance energy expenditures, as a function of $\mathrm{BW}^{0.75}$, was obtained for each of the 21 data sets. The average expenditure was $0.097 \pm$ $0.004 \mathrm{Mcal}$ of $\mathrm{NE}_{\mathrm{L}} / \mathrm{kg}$ of $\mathrm{BW}^{0.75}$ (Table 2). An adjusted mean, eliminating 2 values that were likely sources of errors (data sets 10 and 19), was $0.096 \pm 0.003 \mathrm{Mcal}$ of $\mathrm{NE}_{\mathrm{L}} / \mathrm{kg}$ of $\mathrm{BW}^{0.75}$, a $1 \%$ change that reduced $\mathrm{SE}$ by $25 \%$. In addition, second-order polynomial equations relating weekly maintenance estimates to WOL were parameterized for each of the 21 data sets (Table 2), and for the average of weekly estimates obtained (Table 2, Figure 2). The average maintenance energy expenditure at the onset of lactation was approximately $0.08 \mathrm{Mcal}$ 
Table 2. Individual and averaged time-independent maintenance equations (Mcal of $\mathrm{NE}_{\mathrm{I}} / \mathrm{kg}_{\mathrm{g}}$ of $\mathrm{BW}^{0.75}$ ) and time-dependent maintenance energy expenditure equations

\begin{tabular}{|c|c|c|c|c|c|c|}
\hline \multirow[b]{3}{*}{ Data set } & \multirow{2}{*}{\multicolumn{2}{|c|}{$\begin{array}{l}\text { Time-independent } \\
\text { maintenance equation }\end{array}$}} & \multicolumn{4}{|c|}{$\begin{array}{l}\text { Time-dependent } \\
\text { maintenance equation }\end{array}$} \\
\hline & & & \multirow{2}{*}{$\begin{array}{l}\text { Intercept } \\
\left(10^{-3}\right)\end{array}$} & \multirow{2}{*}{$\begin{array}{l}\text { Week of } \\
\text { lactation } \\
\left(10^{-3}\right)\end{array}$} & \multirow{2}{*}{$\begin{array}{l}\text { Week of } \\
\text { lactation }{ }^{2} \\
\left(10^{-3}\right)\end{array}$} & \multirow[b]{2}{*}{$\mathrm{r}^{2}$} \\
\hline & Value & $\mathrm{RSS}^{3}$ & & & & \\
\hline 1 & 0.114 & 22,850 & 52.46 & 6.774 & -0.1313 & 0.823 \\
\hline 2 & 0.091 & 1,851 & 76.10 & 2.066 & -0.0457 & 0.272 \\
\hline 3 & 0.120 & 2,554 & 101.19 & 2.338 & -0.0497 & 0.455 \\
\hline 4 & 0.097 & 854 & 90.60 & 0.835 & -0.0143 & 0.115 \\
\hline 5 & 0.109 & 203 & 109.30 & -0.427 & 0.0025 & 0.108 \\
\hline 6 & 0.107 & 1,261 & 107.41 & -1.097 & 0.0300 & 0.069 \\
\hline 7 & 0.108 & 1,451 & 105.82 & -0.614 & 0.0140 & 0.010 \\
\hline 8 & 0.102 & 2,970 & 105.89 & -1.724 & 0.0472 & 0.138 \\
\hline 9 & 0.108 & 906 & 110.65 & -2.249 & 0.0524 & 0.155 \\
\hline 10 & 0.135 & 2,554 & 127.31 & 0.595 & -0.0237 & 0.232 \\
\hline 11 & 0.102 & 5,319 & 107.57 & -0.277 & 0.0060 & 0.001 \\
\hline 12 & 0.110 & 2,437 & 110.82 & -0.136 & 0.0097 & 0.098 \\
\hline 13 & 0.111 & 12,326 & 84.55 & 1.809 & -0.0244 & 0.573 \\
\hline 14 & 0.070 & 2,231 & 59.12 & 1.055 & -0.0165 & 0.208 \\
\hline 15 & 0.072 & 990 & 70.71 & 0.063 & 0.0038 & 0.171 \\
\hline 16 & 0.083 & 1,539 & 67.16 & 0.461 & -0.0048 & 0.213 \\
\hline 17 & 0.079 & 12,108 & 43.59 & 2.080 & -0.0266 & 0.823 \\
\hline 18 & 0.075 & 1,436 & 69.57 & 0.402 & 0.0005 & 0.183 \\
\hline 19 & 0.068 & 2,909 & 74.51 & -1.332 & 0.0466 & 0.231 \\
\hline 20 & 0.086 & 948 & 90.45 & -1.994 & 0.0529 & 0.176 \\
\hline 21 & 0.086 & 1,019 & 97.47 & -2.733 & 0.0697 & 0.116 \\
\hline Average & $0.096( \pm 0.003)^{4}$ & & $78.09( \pm 4.92)$ & $1.352( \pm 0.456)$ & $-0.0227( \pm 0.0098)$ & 0.804 \\
\hline
\end{tabular}

${ }^{1}$ The maintenance equation ( $\mathrm{Mcal}$ of $\mathrm{NE}_{\mathrm{L}} / \mathrm{kg}$ of $\mathrm{BW}^{0.75}$ ) that resulted in the least residual sum of squares for that data set for the entire lactation period.

${ }^{2}$ The quadratic equation that described maintenance energy expenditures $\left(\mathrm{Mcal}\right.$ of $\mathrm{NE}_{\mathrm{L}} / \mathrm{kg}$ of $\mathrm{BW}^{0.75}$ ) for that data set for the entire lactation period, determined by fitting an equation to weekly maintenance energy expenditure estimates that resulted in zero difference between predicted and observed BW.

${ }^{3} \mathrm{RSS}=$ Residual sum of squares

${ }^{4}$ Mean \pm SEM, deleting 2 data sets likely contributing error.

of $\mathrm{NE}_{\mathrm{I}} / \mathrm{kg}$ of $\mathrm{BW}^{0.75}$. This value increased until wk 15 of lactation where it plateaued at approximately 0.098 Mcal of $\mathrm{NE}_{\mathrm{L}} / \mathrm{kg}$ of $\mathrm{BW}^{0.75}$ (Figure 2).

Plots of predicted vs. observed $\mathrm{BW}$ and residual $\mathrm{BW}$ vs. WOL obtained from simulations with the 2 new descriptions of maintenance expenditures are presented in Figures 3 and 4. The 0.096 time-independent equation and the time-dependent equation corrected the overprediction seen with the original 0.08 factor, but a large degree of variation remains evident.

Root MSPE for the original maintenance factor was $14.5 \%$ of the observed mean (Table 3). The 0.096 timeindependent maintenance equation reduced root MSPE to $10.9 \%$, and the new average maintenance equation reduced it to $11.2 \%$. As root MSPE decreased, the proportion of MSPE from random sources (error due to disturbances) increased (Table 3). The new estimates reduced error due to mean bias to less than $1 \%$ for the 0.096 factor and average equation, where the original factor resulted in $30.2 \%$ of MSPE arising from mean bias.
Both new maintenance descriptions improved BW predictions of the energy balance model when compared with the original 0.08 maintenance equation (Table 3 ). Overall, the new 0.096 time-independent maintenance equation yielded the lowest RSS and MSPE values. Each of the new maintenance prediction scenarios resulted in average predicted BW substantially lower than that for the original 0.08 factor (Table 3 ) indicating that the BW overprediction was corrected. In predicted vs. observed plots, the regression lines were not significantly different from the line of unity for the 0.096 timeindependent equation or the time-dependent maintenance equation (for the 0.096 equation: intercept $=$ $-46.1 \pm 223.3$, slope $=1.14 \pm 0.41$; for the time-dependent equation: intercept $=367.5 \pm 263.9$, slope $=0.45$ \pm 0.47 ). Plots of residual BW vs. WOL were also not significant; however, plots of residual vs. predicted BW yielded significant regression equations (linear equation for 0.096 maintenance equation slope $=1.09 \pm 0.17$, intercept $=-600.88 \pm 100.5$; linear equation for time- 


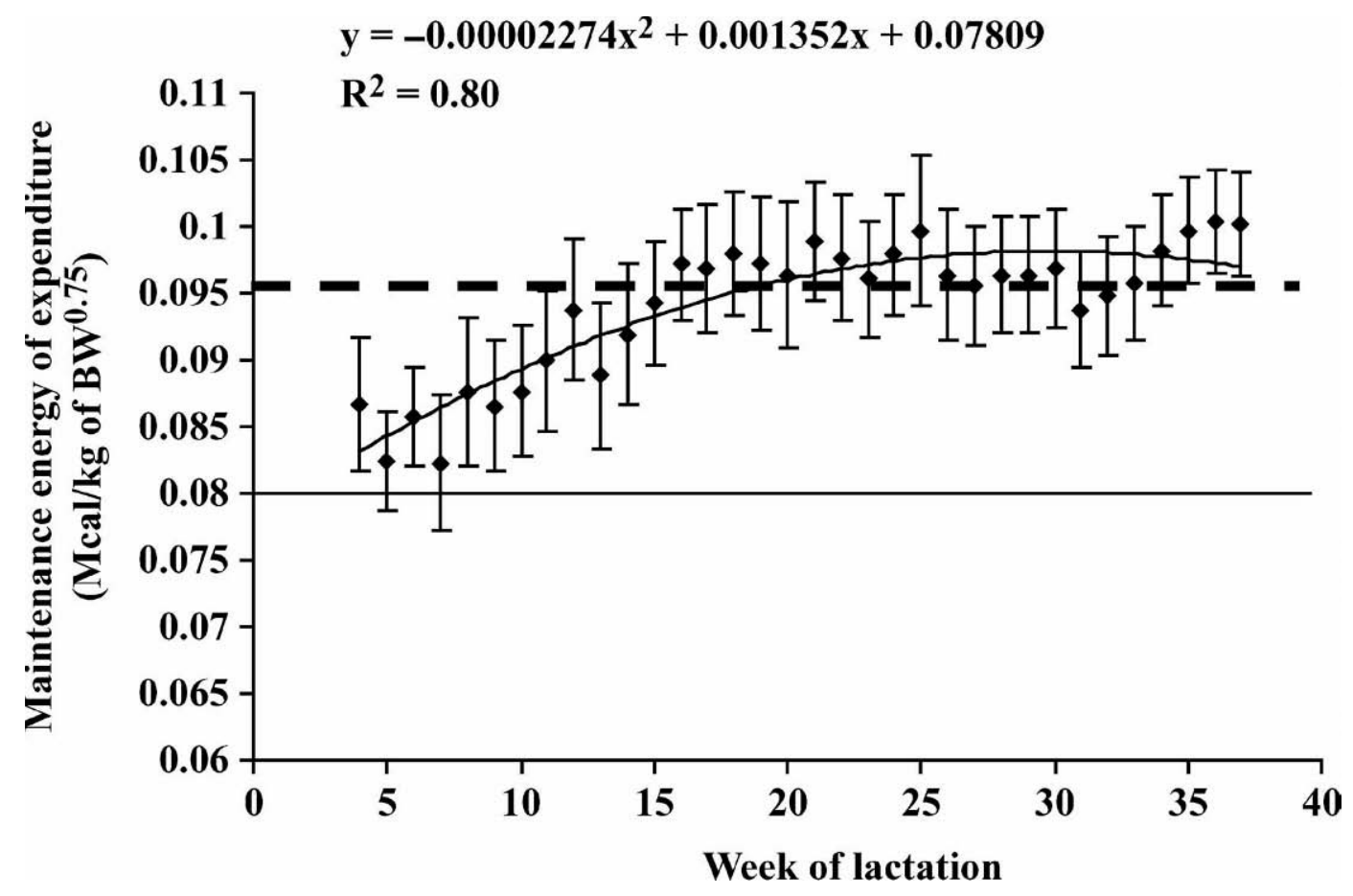

Figure 2. Maintenance energy expenditures (Mcal of $\mathrm{NE}_{\mathrm{L}} / \mathrm{kg}$ of $\mathrm{BW}^{0.75}$ ) vs. week of lactation where the bottom solid line represents the original $0.08 \times \mathrm{BW}^{0.75}$ maintenance equation, the top dashed line represents the least residual sum of squares determined time-independent $0.096 \times \mathrm{BW}^{0.75}$ equation, and the fitted line is the time-dependent maintenance energy expenditure equation $( \pm \mathrm{SE})$ determined by averaging weekly estimates that resulted in zero difference between predicted and observed BW.

dependent maintenance equation slope $=0.847 \pm 0.178$, intercept $=-456.19 \pm 98.59$ ).

\section{DISCUSSION}

The preceding work was undertaken to evaluate, and correct if necessary, the cumulative energy balance implied by weekly observations of DMI, BW, and FCM production over the course of a full lactation. Equations of the NRC $(1988,2001)$ were used to make the evaluations, which clearly showed a trend for BW to be overpredicted as lactation progressed (Figure 1). This cumulative error is consistent with errors reported by others (McNamara and Baldwin, 2000; Heuer et al., 2001). To use these energy balance calculations for evaluation of DMI predictions in a dynamic model, as was our intent (Ellis et al., 2006), we were obliged to first attempt to correct the apparent bias. A review of the literature suggested that the NRC (2001) maintenance energy expenditures are underpredicted during lactation by anywhere from 10 to $49 \%$ (for examples see Ritzman and Benedict, 1938; Ferrell and Jenkins, 1987; Kebreab et al., 2003). Although maintenance is likely not the only source of error in this energy balance estimation, and whereas a higher maintenance expenditure during lactation is indistinguishable from a lower efficiency of conversion of dietary $\mathrm{ME}$ to $\mathrm{NE}_{\mathrm{L}}$, the bias correction was simplified by putting it all in one place, that being the estimate of maintenance energy expenditures. The value of $0.096 \mathrm{Mcal}$ of $\mathrm{NE}_{\mathrm{L}} / \mathrm{kg}$ of $\mathrm{BW}^{0.75}$, a $20 \%$ increase over NRC (2001), substantially improved BW prediction, where $\mathrm{BW}$ was predicted dynamically from $\mathrm{NE}_{\mathrm{L}}$ balance and then used in calculating maintenance $\mathrm{NE}_{\mathrm{L}}$ expenditures. On average, using the new maintenance term equaled approximately an additional $1.84 \mathrm{Mcal} /$ $\mathrm{d}$, or $6.5 \%$ of $\mathrm{NE}_{\mathrm{L}}$ intake. Although parameters of the predicted BW vs. observed BW and residual BW vs. WOL plots became nonsignificant with modification of the maintenance description, residual BW vs. predicted BW plots were still significant and indicated that the model remains in need of further improvements.

Weighting time-independent and time-dependent maintenance equations by the number of cows per treatment result in a time-independent maintenance equation of $0.94 \mathrm{Mcal}$ of $\mathrm{NE}_{\mathrm{L}} / \mathrm{kg}$ of $\mathrm{BW}^{0.75}$, and a time-dependent equation of: Maintenance $\mathrm{NE}_{\mathrm{L}}=[-0.00002014 \times$ $\left.\mathrm{WOL}^{2}+0.00122316 \times \mathrm{WOL}+0.07643808\right]$ Mcal of $\mathrm{NE}_{\mathrm{L}} /$ $\mathrm{kg}$ of $\mathrm{BW}^{0.75}$, in which the same 2 data sets were removed as in the original scenario. Thus, weighting had little effect on the parameter estimates. Although weighting can remove bias in parameter estimates introduced by data sets with a low n, the goal of our 

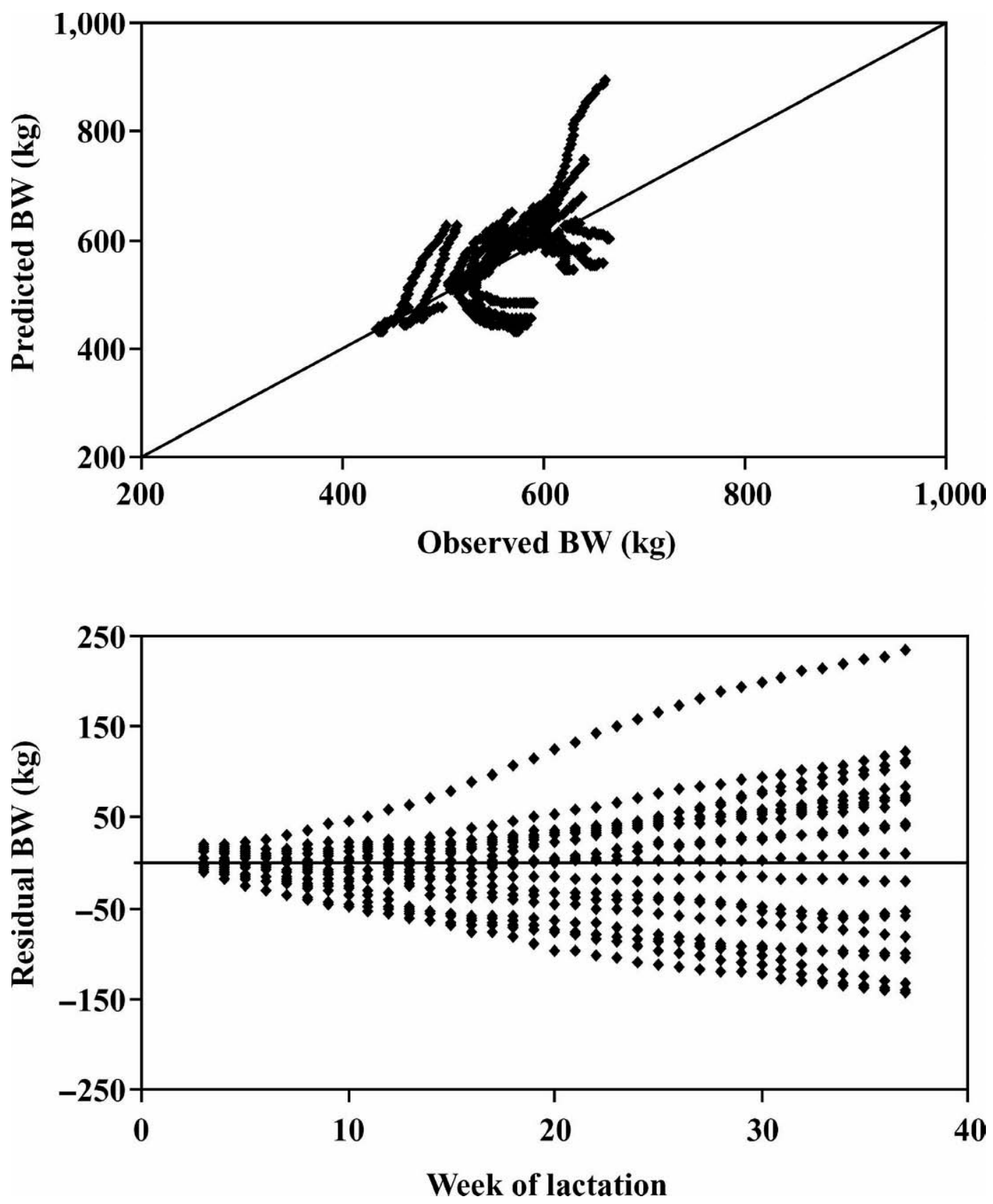

Figure 3. Predicted vs. observed BW (top) and residual (Predicted - Observed) BW vs. week of lactation (bottom) in the model of energy balance using the $0.096 \mathrm{Mcal}$ of $\mathrm{NE}_{\mathrm{L}} / \mathrm{kg}$ of $\mathrm{BW}^{0.75}$ time-independent maintenance equation.

subsequent work (Ellis et al., 2006) was to attempt to correct bias through a biological feedback of energy stores onto DMI predictions instead of a statistical weighting procedure. Using weighted maintenance parameters would result in maintenance expenditures further away from what some individual data sets need to correct the energy balance problem, and this additional error would have to be absorbed by the feedback mechanism. For this reason, although we present the weighted factors, the unweighted factors were focused on for model development.

\section{Potential Sources of Error}

Components of the energy balance model other than the maintenance calculation could have contributed to the error in BW prediction. Milk production, expressed as kilograms of 4\% FCM (Gaines, 1928), allows a con- 

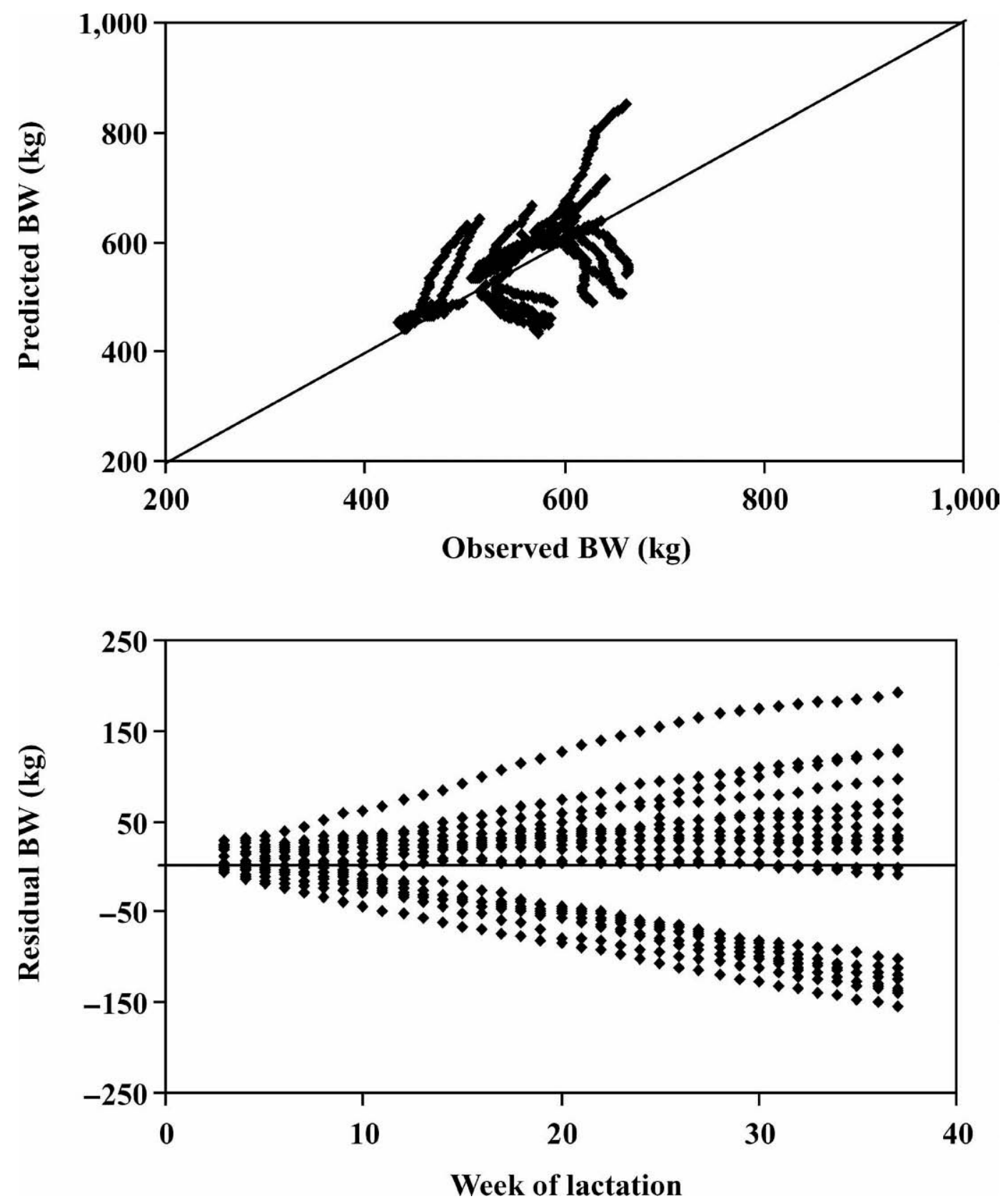

Figure 4. Predicted vs. observed BW (top) and residual (Predicted - Observed) BW vs. week of lactation (bottom) in the model of energy balance using the time-dependent maintenance equation.

stant energy content of $0.749 \mathrm{Mcal}$ of $\mathrm{NE}_{\mathrm{L}} / \mathrm{kg}$ to be used (NRC, 2001), except when milk fat is less than $3 \%$ (NRC, 2001), such as during milk fat depression due to dietary manipulation (Weiss, 2002). In the performance data used for model evaluation here, none of the average milk fat percentages fell below $3 \%$, and milk fat depression was not evident or reported. It is unlikely, then, that using $4 \%$ FCM to describe milk production substantially contributed to the error in energy balance seen here.
A second potential source of error is calculation of the energy content of the feed. The NRC (2001) computer model program is commonly used to calculate dietary $\mathrm{NE}_{\mathrm{L}}$ in North America, and is an improvement over the NRC (1988) method of determination. In 2 separate evaluations of accuracy, $\mathrm{NE}_{\mathrm{L}}$ values for feeds according to NRC (1989) were 5\% (Weiss, 1998) and 5 to 7\% (Vermorel and Coulon, 1998) too high, whereas with the NRC (2001) method, overprediction of dietary $\mathrm{NE}_{\mathrm{L}}$ was decreased to $1.2 \%$ (Weiss, 1998). Depending 
Table 3. Summary of BW predictions by the energy balance model using all observed values as inputs, and maintenance energy expenditures were described by either the original maintenance equation, the new time-dependent equation, or the time-dependent equation

\begin{tabular}{|c|c|c|c|c|c|c|c|}
\hline & \multicolumn{2}{|c|}{ Predicted $\mathrm{BW}^{1}$} & \multirow{2}{*}{$\begin{array}{l}\text { Root } \\
\text { MSPE, }{ }^{2} \%\end{array}$} & \multicolumn{3}{|c|}{ MSPE } & \multirow{2}{*}{$\begin{array}{l}\text { Residual } \\
\text { sum of } \\
\text { squares }^{6}\end{array}$} \\
\hline & Mean & SEM & & $\mathrm{ECT},{ }^{3} \%$ & $\mathrm{ER},{ }^{4} \%$ & $\mathrm{ED},{ }^{5} \%$ & \\
\hline Original 0.08 equation $^{7}$ & $602.8 *$ & 2.1 & 14.5 & 30.2 & 42.9 & 27.0 & $4,825,722$ \\
\hline Time-independent 0.096 equation $^{8}$ & 556.2 & 3.0 & 10.9 & 0.1 & 49.4 & 50.6 & $2,734,479$ \\
\hline Time-dependent equation ${ }^{9}$ & 559.6 & 2.7 & 11.2 & 0.1 & 41.4 & 58.6 & $2,873,146$ \\
\hline
\end{tabular}

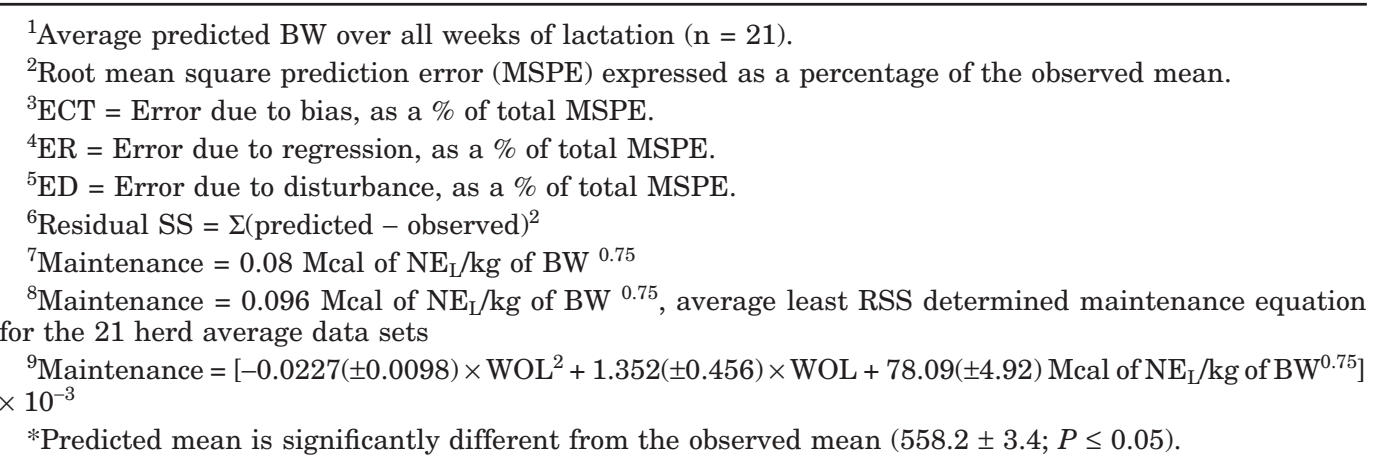

on the feed used, prediction of dietary energy content with this methodology may partially contribute to poor prediction of BW within an energy balance model. However, the $1.2 \%$ overprediction reported by Weiss (1998) is not large enough to account for the degree of BW overprediction evident in this study. Adjustment downwards of dietary $\mathrm{NE}_{\mathrm{L}}$ within the model by $1.2 \%$ decreased the average predicted BW from 602.7 to 593.9 $\mathrm{kg}$ and decreased the total RSS by approximately $15 \%$. Adjusting dietary $\mathrm{NE}_{\mathrm{L}}$ accounted for only $8.8 \mathrm{~kg}(20 \%)$ of the average $44.5-\mathrm{kg}$ BW overprediction, leaving $80 \%$ of the BW overprediction unaccounted for. Although calculation of dietary $\mathrm{NE}_{\mathrm{L}}$ using the $\mathrm{NRC}$ (2001) methodology might have contributed to error in predicted BW within the energy model, it was not the major contributing factor. However, until systems that can more accurately represent the true dietary $\mathrm{NE}_{\mathrm{L}}$ are available, these limitations must be acknowledged and accepted as likely having a role in contributing to errors in energy balance calculations.

In this study, the energetic cost of pregnancy was not included in the estimation of energy balance. There is usually little or no increase in energy requirements due to pregnancy during lactation, and thus any increases in energy expenditures due to pregnancy would not come into play until after the cessation of lactation (Bauman and Currie, 1980). Because none of the data sets used here extended beyond 37 WOL, excluding pregnancy did not contribute to overprediction of BW. In addition, calf weight should not significantly affect average daily gain of the cow until days pregnant is greater than 190, or approximately 40 WOL (NRC, 2001). Thus, the actual weight of the fetus would not affect observed BW against which the predicted values, which do not consider fetus weight, were tested.

Another source of error to be considered is that changes in BW may not always reflect changes in retained tissue energy (NRC, 1988). From wk 5 to 12 , energy reserves can differ by $40 \%$ with no change in BW (NRC, 1988), due to rapid changes in DMI and gut fill. Chilliard et al. (1991) found that a 4-kg increase in gut fill accompanies a 1-kg increase in DMI, whereas more recent studies (Komaragiri and Erdman, 1997; Komaragiri et al., 1998) suggest a 2.5-kg increase per 1 -kg increase in DMI. Because tissue mobilization occurs at the same time that DMI is rapidly increasing in early lactation, decreases in BW due to depleting energy stores are masked by a simultaneous increase in gut fill. After peak lactation, DMI and gut fill decrease at the same time as body energy stores begin to increase. Although BW may not always accurately represent changes in body tissue weight, the model predicts similar BW at the end of lactation whether the effect of gut fill is included or not and including this effect does not correct the substantial overprediction of BW. If observed BW is adjusted downwards to account for a $2.5-\mathrm{kg}$ increase in gut fill per $1-\mathrm{kg}$ increase in DMI, the overall mean BW changes by $0.03 \%$.

The $\mathrm{NE}_{\mathrm{L}}$ content of $\mathrm{BW}$ gain/loss is another potential source of error. The NRC (1988) values were used here because information on BCS was not available, and is required for the NRC (2001) system. The energy content of gain/loss definitely changes across BCS, and the error in using average equations to describe all cows is acknowledged. However, analysis here showed that this model is fairly insensitive to these values. The energy 
content of gain would have to be increased by over $200 \%$ to correct the discrepancy between predicted and observed BW. Although these factors contribute to overall error, they are likely not the major contributing factor.

Additional maintenance energy expenditures for growing animals were added to the energy balance model for first-lactation data sets only. Unfortunately, not all data sets reported age of the animals used, and all these studies grouped animals in any lactation greater than one together. It is acknowledged that there will be some growth in cows in their second lactation but, determination of which, if any, data sets should be given additional energy expenditures was impossible here. This error is acknowledged, and although it may contribute to some of the error in energy balance calculation, it will remain unaddressed until more descriptive data come available.

The above review suggests that, although errors may exist within components of energy balance calculation other than the maintenance cost, none by itself is substantial enough to account for the degree of BW overprediction reported here. Furthermore, even when adjustments were applied simultaneously to the energy content of feed, gut fill, growth, and the $\mathrm{NE}_{\mathrm{L}}$ content of BW gain and loss, the maintenance energy expenditure equation still has to be increased to approximately $0.090 \mathrm{Mcal} / \mathrm{kg}$ of $\mathrm{BW}^{0.75}$ to correct the remaining $\mathrm{BW}$ overprediction. The body of literature suggesting that maintenance energy expenditures during lactation are currently underestimated (for examples, see Yan et al., 1997; Kirkland and Gordon, 2001; Kebreab et al., 2003) supports the idea that the BW overprediction in this model is caused at least partially by underestimation of maintenance energy expenditures.

\section{Correction of the Bias}

Maintenance energy expenditure by the lactating dairy cow, defined here as the $\mathrm{NE}_{\mathrm{L}}$ equivalent used to maintain the animal, as it is, at zero BW content change, is described by the NRC (2001) as $0.08 \mathrm{Mcal} /$ $\mathrm{kg}$ of $\mathrm{BW}^{0.75}$, based on measured fasting heat production estimates of $0.073 \mathrm{Mcal} / \mathrm{kg}$ of $\mathrm{BW}^{0.75}$ for dry nonpregnant dairy cows housed in tie stalls or metabolic chambers (Flatt et al., 1965). A 10\% allowance for normal voluntary activity of cows that would be housed in dry lot or freestall systems increased the factor to $0.08 \mathrm{Mcal} /$ $\mathrm{kg}$ of $\mathrm{BW}^{0.75}$ (NRC, 2001). The dairy estimates agree with beef cattle estimates (NRC, 1996), in which the base maintenance requirement, $0.065 \mathrm{Mcal} / \mathrm{kg}$ of $\mathrm{BW}^{0.75}$, with a Holstein/Jersey breed adjustment factor of 1.2 , results in a maintenance energy requirement of $0.079 \mathrm{Mcal} / \mathrm{kg}$ of $\mathrm{BW}^{0.75}$.
Several studies have shown that energy expenditures for maintenance are substantially higher than this during lactation. By nonlinear and linear regression analysis of milk energy output on energy intake adjusted to zero energy balance, Kebreab et al. (2003) estimated maintenance energy expenditures to be 16 to $22 \%$ higher during lactation than predicted by NRC (2001). Similarly, Moe et al. (1970) reported a 22\% increase in maintenance energy expenditures based on multiple regression analysis of energy balance data. Although such estimates were based on extrapolation outside the range of observations to zero energy retention, indirect calorimetry has also yielded estimates of the lactation effect on maintenance energy expenditures as an increase of 49\% (Ritzman and Benedict, 1938), 23\% (Flatt et al., 1969), 27\% (Kirkland and Gordon, 2001), and 29\% (Yan, et al., 1997). According to observed changes in $\mathrm{BW}$, maintenance energy expenditures have been estimated to be increased more than $30 \%$ (Neville and McCullough, 1969) or 10 to 20\% (Ferrell and Jenkins, 1987) during lactation.

Smith and Baldwin (1974) showed that organ weights were higher in lactating compared with nonlactating cows for liver $(25 \%)$, heart $(22 \%)$, mammary gland (73\%), lungs (22\%), rumen (20\%), abomasums (35\%), intestines (31\%), spleen (20\%), and adrenals (19\%). Assuming no change in energy expended/weight of tissue, a $10 \%$ increase in energy expenditures during lactation could be attributed to differences in organ tissue weight alone. According to our estimates, maintenance energy expenditures rose until approximately $15 \mathrm{WOL}$, where it plateaued at approximately $0.098 \mathrm{Mcal}$ of $\mathrm{NE}_{\mathrm{L}} / \mathrm{kg}$ of $\mathrm{BW}^{0.75}$ (Figure 2). The 0.096 time-independent equation represents the weighted average of this curve. Interestingly, the $0.08 \mathrm{Mcal}$ of $\mathrm{NE}_{\mathrm{I}} / \mathrm{kg}$ of $\mathrm{BW}^{0.75}$ maintenance equation (NRC, 2001) seems to agree with values obtained here in early lactation (Figure 2). It is only as the demands of lactation increase and lactation persists that maintenance energy expenditures rise to a higher value. It appears that the 0.08 maintenance equation still describes well the energy expenditures of a nonlactating dairy cow. Maintenance energy expenditures rise in early lactation because milk production and DMI both peak within the first 15 WOL, placing increased demands on the internal organs to increase in both size and activity. In comparative slaughter measurements, rumen, small intestine, and liver weights of dairy cattle increased as a percentage of empty BW from 2 to 17 WOL, and then decreased by wk 34 (Baldwin et al., 2004). Similarly, weights of ewe liver and rumen reached a maximum at $6 \mathrm{WOL}$, and small intestines at 4 WOL, and weights declined thereafter (Fell et al., 1972). The increase, plateau, and eventual decline in metabolically active organ size and activity are likely 
associated with a similar pattern in maintenance energy expenditures. Although our data showed no decline in maintenance energy expenditures, it is possible, had the data extended further into late lactation, that a decline would be observed. Some individual data sets did show a decline in maintenance energy expenditures after peak lactation, but averaging curves smoothes out any rise to peak, peak, or eventual decline observed. More extensive data would be required to determine the exact pattern of maintenance energy expenditure change over the course of lactation.

Increased metabolic activity of organs to support lactation could be considered either as a maintenance cost or an inefficiency of conversion of $\mathrm{ME}$ to $\mathrm{NE}_{\mathrm{L}}$. The 2 are actually indistinguishable mathematically and the selection of one over the other remains a matter primarily of philosophical preference. In the NRC (2001) system, an efficiency adjustment to correct the bias we encountered would be accommodated by changing $\mathrm{NE}_{\mathrm{L}}$ values of feedstuffs, which is rather more difficult to do than the alternative maintenance adjustment undertaken here.

The variation in energy balance bias represents a problem in the use of one equation to describe all lactating dairy cows. The between-data set variation in maintenance energy expenditures around the updated 0.096 maintenance equation was $25 \%$. The highest maintenance value was 0.135 and the lowest was $0.068 \mathrm{Mcal}$ of $\mathrm{NE}_{\mathrm{I}} / \mathrm{kg}$ of $\mathrm{BW}^{0.75}$. Although this variation likely encompasses multiple sources of error, others have reported similar, if not higher, degrees of variation. Ritzman and Benedict (1938) found between-animal variation in maintenance energy requirements under uniform conditions of up to $50 \%$ in Holstein and up to $71 \%$ in Jersey cows. Carstens et al. (1989) and Taylor and Young (1968) found that maintenance requirements varied by 20 to $30 \%$ due to genetic differences alone, which appeared moderately to highly heritable.

Genetic potential for production, previous plane of nutrition, estimation of dietary energy content, environment, BCS, and physiological status likely contribute cumulatively to a high degree of variation between animals. It was evident from a review of the literature that maintenance is not a constant function of BW (Webster et al., 1982; Ferrell and Jenkins, 1985). The possible roles of several factors contributing to the variation in energy balance bias reported here were examined. The relationship between maintenance energy expenditures and average BW, average DMI, peak FCM yield, total $\mathrm{FCM}$ yield, and dietary $\mathrm{NE}_{\mathrm{L}}$ content were not significant. In contrast, Ferrell and Jenkins (1987) found that maintenance energy expenditures increased about $9.6 \mathrm{kcal} / \mathrm{kg}$ of $\mathrm{BW}^{0.75}$ per d for each $1-\mathrm{kg}$ increase in milk yield at peak lactation. Interestingly, they re- ported that $40 \%$ of the variation in maintenance energy expenditures could be explained by variation in milk production potential alone.

It is important to reiterate that the maintenance description developed here is essentially an error term, containing errors associated with the other aspects of energy balance calculations discussed above. It was not the goal of this paper to assign individual correction factors to all of these components, but to provide a feasible solution to the model, agreeable with data in the literature, such that the model could be used for further evaluations of DMI prediction equations.

\section{CONCLUSIONS}

Revision of the maintenance energy expenditure estimate substantially improves BW prediction by a dynamic simulation of energy balance. On average, the time-independent $0.096 \mathrm{Mcal}$ of $\mathrm{NE}_{\mathrm{L}} / \mathrm{kg}$ of $\mathrm{BW}^{0.75}$ equation resulted in the best BW predictions, although there was $25 \%$ variation around this value, likely encompassing other sources of error.

The $0.096 \mathrm{Mcal}$ of $\mathrm{NE}_{\mathrm{L}} / \mathrm{kg}$ of $\mathrm{BW}^{0.75}$ equation is $20 \%$ higher than the original $0.08 \mathrm{Mcal}$ of $\mathrm{NE}_{\mathrm{L}} / \mathrm{kg}$ of $\mathrm{BW}^{0.75}$. This increase is in agreement with estimates of maintenance energy expenditures presented in the reviewed literature, which ranged from 10 to $49 \%$, but averaged from 20 to 30\% (for examples see Moe et al., 1970; Yan et al., 1997; Kirkland and Gordon, 2001). This new timeindependent equation, as well as a time-dependent quadratic equation relating maintenance expenditures to WOL, are useful in better describing energy balance within a dynamic model, but do little to account for the substantial variation that is evident. It is the goal of the companion paper (Ellis et al., 2006) to address betweendata set variation and correction of errors that persist in accumulating over time.

\section{ACKNOWLEDGMENTS}

The authors would like to thank Mike Messman and Richard Spratt from Cargill Animal Nutrition for their efforts throughout this project. This work was funded by a grant-in-aid from Agribrands International, a wholly owned subsidiary of Cargill, Inc., NSERC Canada, and the Ontario Ministry of Agriculture and Food.

\section{REFERENCES}

Baldwin, R. L. 1995. Modeling Ruminant Digestion and Metabolism. Chapman \& Hall, London, UK.

Baldwin, R. L., K. R. McLeod, and A. V. Capuco. 2004. Visceral tissue growth and proliferation during the bovine lactation cycle. J. Dairy Sci. 87:2977-2986.

Bauman, D. E., and W. B. Currie. 1980. Partitioning of nutrients during pregnancy and lactation: A review of mechanisms involving homeostasis and homeorhesis. J. Dairy Sci. 63:1514-1529. 
Bibby, J., and H. Toutenburg. 1977. Prediction and Improved Estimation in Linear Models. John Wiley \& Sons, Chichester, UK.

Carstens, G. E., D. E. Jonnson, K. A. Johnson, S. K. Hotovy, and T. J. Szymanski. 1989. Genetic variation in energy expenditures of monozygous twin beef cattle at 9 and 20 months of age. Pages 312-315 in Energy Metabolism of Farm Animals No. 11. Eur. Assoc. Anim. Prod. Publ. No. 43, Lunteren, Netherlands.

Chilliard, Y., M. Cisse, R. LeFaivre, and B. Remond. 1991. Body composition of dairy cows according to lactation stage, somatotropin treatment, and concentrate supplementation. J. Dairy Sci. 74:3103-3116.

DePeters, E. J., N. E. Smith, and J. Acedo-Rico. 1985. Three or 2 times daily milking in older cows and first lactation cows for entire lactations. J. Dairy Sci. 68:123-132.

Ellis, J. L., Qiao, F., Cant, J. P. 2006. Prediction of dry matter intake throughout lactation in a dynamic model of dairy cow performance. J. Dairy Sci. 89:1558-1570.

Fell, B. F., R. M. Campbell, W. S. Mackie, and T. E. C. Weekes. 1972. Changes associated with pregnancy and lactation in some extrareproductive organs of the ewe. J. Agric. Sci. (Camb.) 79:397-407.

Ferrell, C. L., and T. G. Jenkins. 1985. Cow type and the nutritional environment: nutritional aspects. J. Dairy Sci. 61:725-741.

Ferrell, C. L., and T. G. Jenkins. 1987. Influence of biological type on energy requirements. Pages 1-7 in Proc. Grazing Livest. Nutr. Conf. Misc. Publ., Agric. Exp. Stn., Oklahoma State Univ., Stillwater.

Flatt, W. P., C. E. Coppock, and L. A. Moore. 1965. Energy balance studies with dry, non-pregnant dairy cows consuming pelleted forages. Page 131 in Energy Metabolism of Farm Animals No. 3. Eur. Assoc. Anim. Prod. Publ. No. 11. Troon, UK.

Flatt, W. P., P. W. Moe, and L. A. Moore. 1969. Influence of Pregnancy and Ration Composition on Energy Utilization by Dairy Cows. Page 123 in Energy Metabolism of Farm Animals No. 4. Eur. Assoc. Anim. Prod. Publ. No. 12, Warsaw, Poland.

Gaines, W. L. 1928. The energy basis of measuring milk yield in dairy cows. 1928. Page 40 in Ill. Exp. Res. Stat. Bull. No. 308. Univ. Illinois, Champaign.

Heuer, C., W. M. Van Straalen, Y. H. Schukken, A. Dirkzwager, and J. P. T. M. Noordhuizen. 2001. Prediction of energy balance in high yielding dairy cows with test-day information. J. Dairy Sci. 84:471-472.

Holter, J. B., and H. H. Hayes. 1992. Weekly balancing crude protein in diets for Holstein cows throughout lactation using one versus two grains. J. Dairy Sci. 75:2473-2483.

Holter, J. B., H. H. Hayes, N. Kierstead, and J. Whitehouse. 1993. Protein-fat bypass supplement for lactating dairy cows. J. Dairy Sci. 76:1342-1352.

Kebreab, E., J. France, R. E. Agnew, T. Yan, M. S. Dhanoa, J. Dijkstra, D. E. Beever, and C. K. Reynolds. 2003. Alternatives to linear analysis of energy balance data from lactating dairy cows. J. Dairy Sci. 86:2904-2913.

Kirkland, R. M., and F. J. Gordon. 2001. An examination of metabolic energy requirements of lactating dairy cows. Br. Soc. Anim. Sci. 106:207.

Komaragiri, M. V. S., D. P. Casper, and R. A. Erdman. 1998. Factors affecting body tissue mobilization in early lactation dairy cows. 2. Effect of dietary fat on mobilization of body fat and protein. J. Dairy Sci. 81:169-175.
Komaragiri, M. V. S., and R. A. Erdman. 1997. Factors affecting body tissue mobilization in early lactation dairy cows. 1. Effect of dietary protein on mobilization of body fat and protein. J. Dairy Sci. 80:929-937.

McNamara, J. P., and R. L. Baldwin. 2000. Estimation of parameters describing lipid metabolism in lactation: challenge of existing knowledge described in a model of metabolism. J. Dairy Sci. 83:128-143.

Moe, P. W., H. F. Tyrrell, and W. P. Flatt. 1970. Partial efficiency of energy use for maintenance, lactation, body gain, and gestation in the dairy cow. Page 65 in Energy Metabolism of Farm Animals No. 4. Eur. Assoc. Anim. Prod. Publ. No. 13, Vitznau, Switzerland. Mohrenweiser, H. W., and J. D. Donker. 1967. Forage evaluation. II. Productive response of first-calf Holstein heifers fed early-cut or late-cut alfalfa hay as the only source of energy throughout a total lactation. J. Dairy Sci. 51:367-372.

National Research Council. 1988. Nutrient Requirements of Dairy Cattle. 6th rev. ed. National Academy Press, Washington, DC.

National Research Council. 1996. Nutrient Requirements of Beef Cattle. 7th rev. ed. National Academy Press, Washington, DC.

National Research Council. 2001. Nutrient Requirements of Dairy Cattle. 7th rev. ed. National Academy Press, Washington, DC.

Neville, W. E., Jr., and M. E. McCullough. 1969. Calculated energy requirements of lactating and non-lactating Hereford cows. J. Anim. Sci. 29:823-829.

Ritzman, E. G., and F. G. Benedict. 1938. Pages 86-148 in Nutritional Physiology of the Adult Ruminant. Waverly Press, Inc., Baltimore, MD.

SAS Institute. 2000. SAS User's Guide. Statistics. SAS Inst., Inc., Cary, NC.

Smith, N. E., and R. L. Baldwin. 1974. Effects of breed, pregnancy, and lactation on weight of organs and tissues in dairy cows. J. Dairy Sci. 57:1055-1060.

Taylor, S. T. C. S., and G. B. Young. 1968. Equilibrium weight in relation to food intake and genotype in twin cattle. Anim. Prod. 10:393-412.

Vermorel, M., and J. B. Coulon. 1998. Comparison of the national research council energy system for lactating cows with for European systems. J. Dairy Sci. 81:846-855.

Webster, A. J. F., J. S. Smith, and G. S. Mollison. 1982. Energy requirements of growing cattle: effects of sire breed, plane of nutrition, sex and season on predicted basal metabolism. Pages 84-87 in Energy Metabolism of Farm Animals No. 9. Eur. Assoc. Anim. Prod. Publ. No. 29, Lillehammer, Norway.

Weiss, W. P. 1998. Estimating the available energy content of feeds for dairy cattle. J. Dairy Sci. 81:830-839.

Weiss, W. P. 2002. Overview and application of the 2001 NRC energy system. Pages 1-15 in Proc. 13th Annu. Florida Rumin. Nutr. Symp., Gainesville, FL. Univ. Florida, Gainesville.

Wohlt, J. E., and J. H. Clark. 1978. Nutritional value of urea versus preformed protein for ruminants. I. Lactation of dairy cows fed corn based diets containing supplemental nitrogen from urea and/ or soybean meal. J. Dairy Sci. 61:902-915.

Yan, T., F. J. Gordon, C. P. Ferris, R. E. Agnew, M. G. Porter, and D. C. Patterson. 1997. The fasting heat production and effect of lactation on energy utilization by dairy cows offered forage-based diets. Livest. Prod. Sci. 52:177-186. 